\title{
A Size-Independent Revision of the Fractal Step Method for Ammonite Sutures
}

\author{
Katherine Marriott ${ }^{1}$ and John A. Chamberlain, Jr. ${ }^{2}$
}

1 KM-Department of Earth and Environmental Sciences, Brooklyn, NY, 11210, USA

2 JAC-Department of Earth and Environmental Sciences, Brooklyn, NY, 11210, USA; PhD Programs in Earth and Environmental Sciences, and in Biology, Graduate Center of the City University of New York, New York, NY 10016, USA

* Correspondence: katelomedicomarriott@gmail.com, johnc@brooklyn.cuny.edu Tel.: (845) 264-4728 (KM)

\begin{abstract}
The novel coronavirus has presented specimen-access challenges to geoscientific researchers, including paleobiologists interested in fossil ammonoids. Ammonoid sutures are geometric patterns formed by the intersection of the septa and the shell wall, and have long been a diagnostic tool for ammonite researchers for such applications as species identification, taxonomic relationships, ontogenetic change, functional and evolutionary morphology, and other aspects of ammonoid paleobiology. Without access to specimens in museum and institutional collections, researchers must rely on previously published illustrations and photographs of ammonoid sutures. However, many of these illustrations were published decades ago without an index of scale. Suture tracings lacking a scale bar are not usable by researchers interested in applying the quantitativeness of fractal geometry to the interpretation of septal complexity. Additonally, distortion of the marginal elements of suture geometry occurs due to shell curvature near the venter and umbilicus. The revised approach described here eliminates the problem of missing scale information in fractal analysis of ammonite sutures, making use of just the lateral lobe and adjacent saddle (lateral lobe-saddle pairs). Our revised method's non-requirement of a full hemisuture also facilitates comparisons among sutures within an ontogenetic sequence, or sutures from multiple ammonite taxa.
\end{abstract}

Keywords: ammonite; sutures; fractal geometry; ammonoid paleobiology; functional morphology; ontogeny

\section{Introduction}

Without access to collections due to widespread and prolonged shutdown of institutions, reliance on ammonoid suture tracings which were published prior to the onset of the COVID-19 pandemic has become one of the primary ways in which those studying suture complexity can continue their work. Suture complexity is an amalgamation of the degree of infolding of the suture, and the geometric arrangement of the folds. [1] Suture geometry, a component of suture complexity, has potentially significant but incompletely-understood implications for ammonoid paleobiology, including; habitat preferences, particularly with respect to water depth; phylogeny, and ontogeny.

Historically, attempts to quantify ammonoid suture complexity have often involved viewing suture patterns as self-similar entities approximating fractals $[\underline{2}, \underline{3}, \underline{4}, \underline{5}, \underline{6}, \underline{8}, \underline{9}$, $\underline{10}, \underline{11}, \underline{12}]$. Fractals are mathematical constructs in which an infinite number of subdivisions can occur on an object, such that each subdivision is a perfect identical miniature 
of the greater whole [13]. The method has been appropriated from shoreline measurement, and can be applied to the quantification of any uneven natural surface or edge which sufficiently resembles the fractal property of self-similarity [7 $\underline{14}]$. However, many of the available published sutures $[\underline{15}, \underline{16}, \underline{17}, \underline{18}, \underline{19}]$ have been published without a scale bar, rendering them useless in fractal-geometry studies attempting to quantify their complexity. This has been cause for us to create a revision of the old equation, which is ultimately more useful than the old method when quantifying the true increase in geometric complexities of suture geometry within the ontogeny of an ammonite.
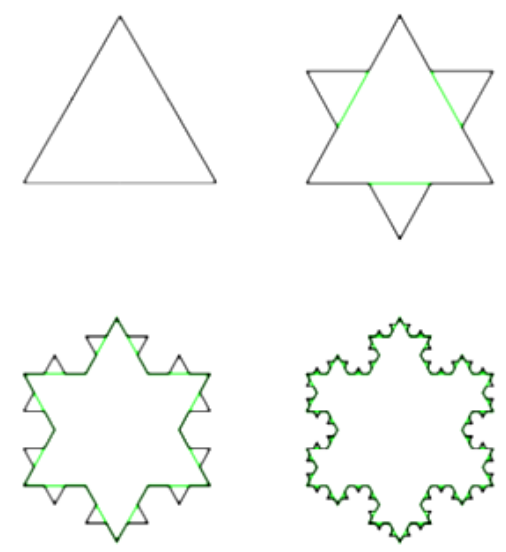

Figure 1. A representation of the Koch Snowflake showing the principle of fractal self-similarity The triangular divisions are perfectly proportional to one another and continue into infinity. Modified from WXS, Wikimedia Commons.

\section{Methods}

1) The Richardson Step Method.

The Richardson Step Method described by [10] requires set step lengths to be chosen at a number of millimeters, such as $10 \mathrm{~mm}$. It is important to consider that longer step lengths, such as $25 \mathrm{~mm}$, provide only general information, and shorter step lengths, such as $5 \mathrm{~mm}$, provide greater accuracy (Figure 2). Conversely, as step length is increased, accuracy and resolution are lost. In ontogenetic studies, shorter step length provides the highest resolution possible, which is necessary due to the limited range of fractal values. 

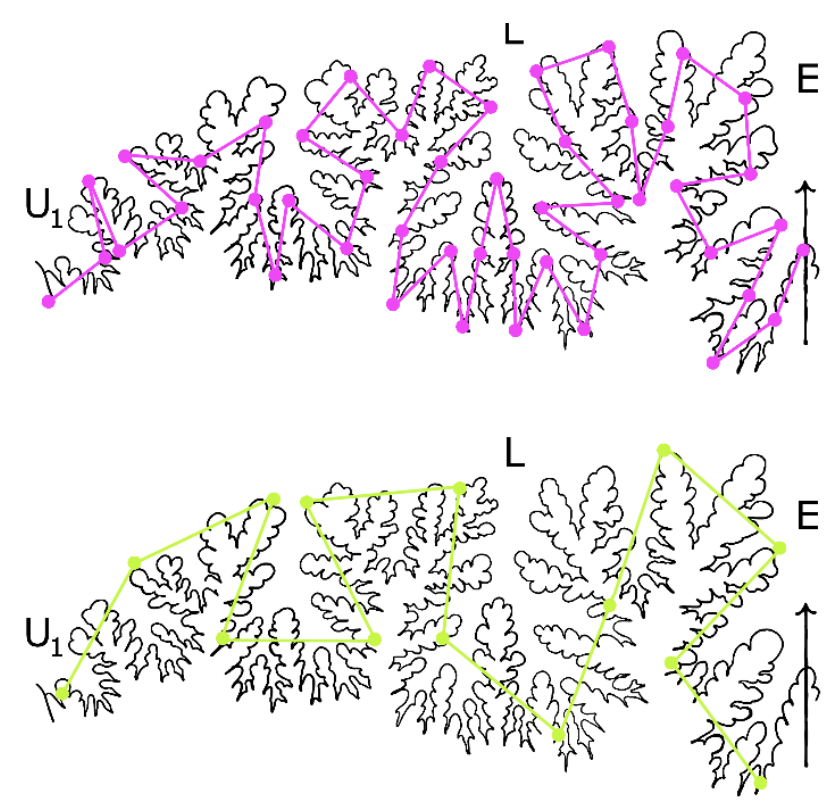

Figure 2. Two step lengths, $1 / 10$ hemisuture (magenta) and 1/5 (green) used to trace the same ammonite suture. The longest step length is the least accurate. Eogaudryceras numidum suture redrawn by one of the authors (KM) from [20, Figure 31E].

One must choose a beginning and end point on the ammonite suture, usually a hemisuture, which is bounded by suture's midpoint, the external lobe, E, and one of its end points, one of the first umbilical lobes, $\mathrm{U}_{1}[\underline{21}]$.

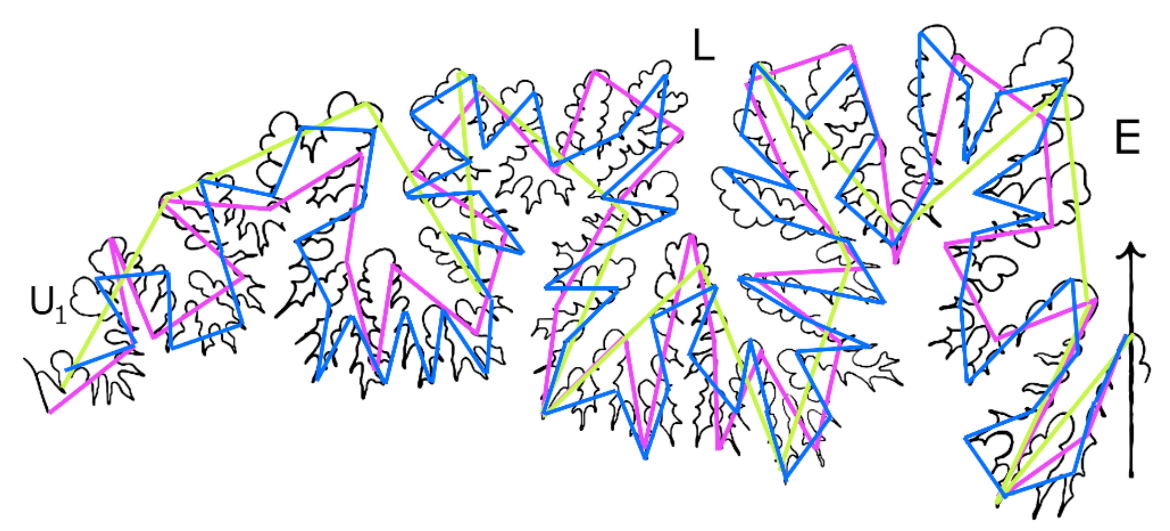

Figure 3. Measurement of Eogaudryceras numidum suture using the Richardson Step Method as described by [12] using fractions of the hemisuture length as step lengths. Green is 1/5, magenta is $1 / 10$, and blue is $1 / 15$. Eogaudryceras numidum suture redrawn by KM from [20, Figure 31E].

Beginning at the center of the External Lobe, one pivots their ruler until 10mm on the ruler intersected the suture line. This is the first step. The second step begins at the end point of the first step, and this will continue until $U_{1}$ is reached. The number of whole steps on the suture are counted. Partial steps are not included.

The number of steps and the number of millimeters in the step length used are plugged into Equation 1:

\section{EQUATION 1}




$$
D(f)=\frac{\log (\# \text { steps })}{\log (\text { units per step })}
$$

where $\mathrm{D}(f)$ is the fractal dimension.

The fractal value for each suture which is measured can then be recorded. In digitized specimens where scale is unavailable, the ontogeny can be represented by the whorl number.

2) The Revised (Covid) Step Method. The Richardson Step Method is not usable without access to scale information, as without scale, it is impossible to determine what step lengths may be used on many published suture tracings and photos. In the Richardson Step Method, step length is chosen with finite measurements that are not based on the dimensions of the specimen, such as units of $20 \mathrm{~mm}, 10 \mathrm{~mm}$, or $5 \mathrm{~mm}$. This makes existing fractal measurements unusable in comparisons between taxa. Unlike the Richardson Step Method, our Revised Step Method enables the use of sutures where only the lateral lobe and one adjacent saddle are visible.

In the Revised Step Method, step length is equal to a given fraction of the length between the base of the lateral lobe (L) and its adjacent saddle on the umbilical-facing side. In Figure 4, the magenta line is the full length of the lateral lobe-saddle pair, and the green line shows a step length of $1 / 10$ the length of the lateral lobe-saddle pair. One-tenth hemisuture lengths were used by [12].

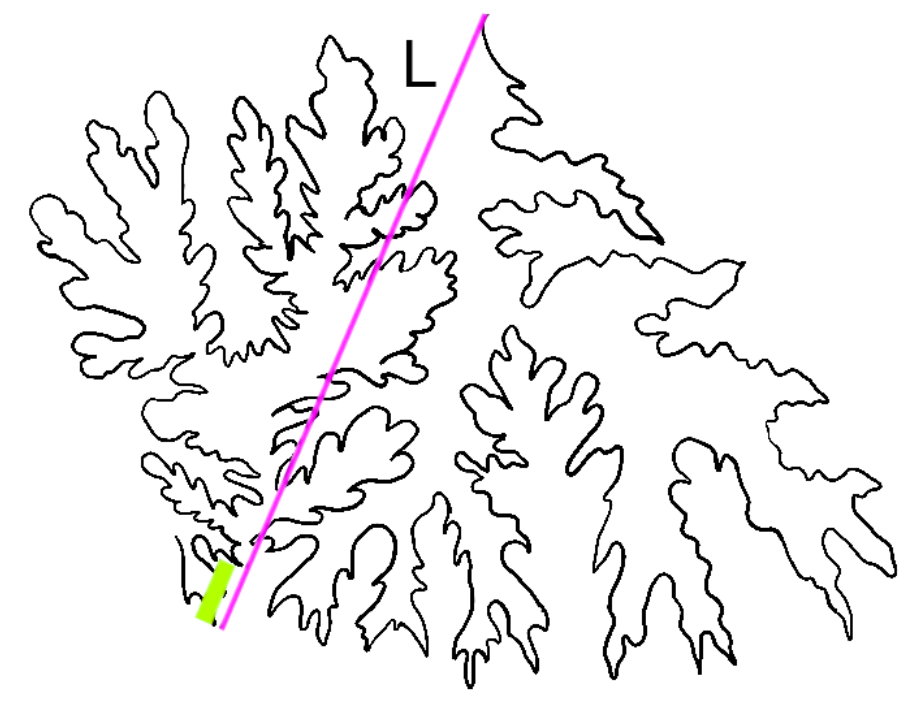

Figure 4. A lateral lobe-saddle pair of Lytoceras taharoaense, the step length (green) is onetenth the distance (magenta) from the base of the lateral lobe (L) to that of its adjacent saddle. Redrawn by KM from [2ㄹ, Figure 23].

In contrast to the Richardson Method, the Revised Step Method measures 
only the lateral lobe and the adjacent saddle (Figures 4-5). Due to the reliance on photographic data during the prolonged closure of institutional collections

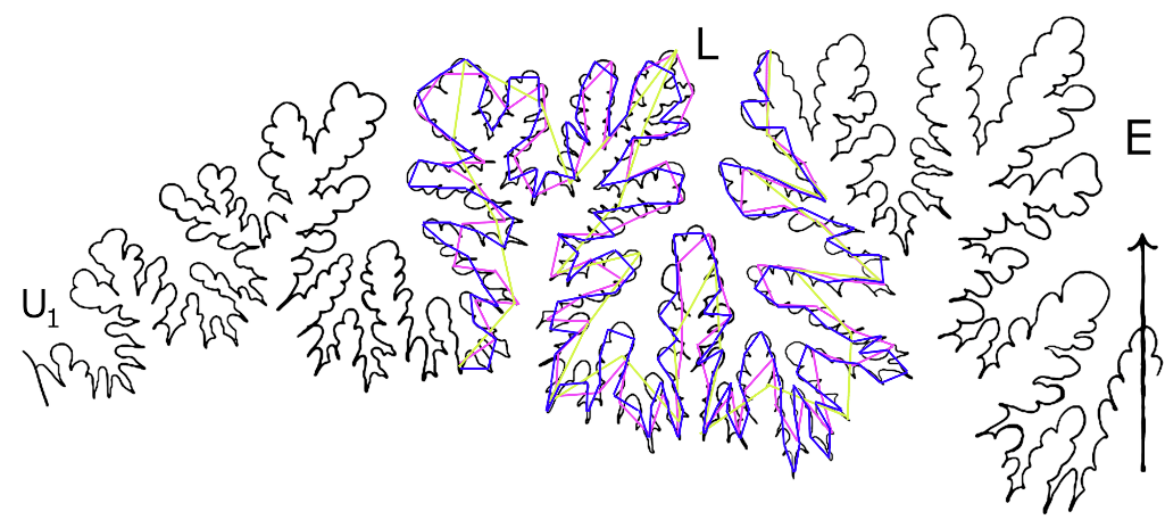

Figure 5. Measurement of Eogaudryceras numidum suture using the Revised Step Method as described using fractions of the hemisuture length as step lengths. Green is 1/5, magenta is $1 / 10$, and blue is $1 / 15$. Eogaudryceras numidum suture redrawn by KM from [20, Figure 31E].

facilities, the acquisition of step length has been modified to include only the lateral lobe (L) and one adjacent saddle from the adjacent saddle adjoining the lateral lobe's umbilical side (Figure 4). Restricting the study to only the nearlyflat section of the hemisuture in most photos allows the portion of a suture with only minimal distortion to be used because doing so eliminates highly distorted sutural images visible where the shell surface and sutures curve downard near the venter and umbilicus. This revised, lateral lobe-saddle pair approach enables photographic evidence to be included in suture research, and may also eliminate challenges with partial preservation.

Because steps are based on fractions the lobe-saddle distance ( $\mathrm{L}$ in Figure 4), steps are smaller in the revised method (Figure 5) compared to the Richardson method (Figure 3). Due to the smaller step lengths used in the revised, lateral lobe-saddle pair method, and the consequently higher step counts, Equation 1 yields higher fractal values for a given lateral lobe-saddle pair than when measuring a full hemisuture using the Richardson method. To ensure that revised method values fall within the ranges for ammonite sutures based on the Richardson method (1 to 2 usually), the steps from the revised method must be converted to a fractal value in the range of the Richardson method's value for that taxon. The number of revised, lobe-saddle steps is then divided by a Conversion Value based on the ammonite's genus. This Conversion Value is determined by measuring a large number of hemisutures in the Richardson (hemisuture) method, and measuring the same sutures in Revised (lateral lobesaddle pair) method to compare step counts from each method.

The number of additional steps measured in the revised method versus the Richardson method varies across genera (see Table 1). Because the number of steps in the revised method for most lytoceratids is almost always exactly twice 
the number of steps when using the Richardson (hemisuture) method, as it is when using the Revised (lateral lobe-saddle pair) method, it is necessary to divide the lytoceratid step count by 2 if only measuring the lateral lobe-saddle pair. Likewise, members of the genus Phylloceras have about 2.5 times the number of steps in the Revised method than they do in the Richardson method, and the lateral step count of a Phylloceras must be divided by 2.5 to determine the correct fractal dimension.

The general geometry of sutures, more than the number of subdivisions, appears to be the driving force behind the variation in conversion values across taxa seen in Table 1. As a result, in some unresolved groups, such as primitive lytoceratids Holcolytoceras and Psiloceras [므, 26], Conversion Values may be indicators of taxonomy.

The Revised fractal equation then becomes:

\section{EQUATION 2:}

$$
C(f)=\frac{\log (\# \text { steps } \div \text { Conversion Value })}{\log (\text { divisions })}
$$

In Equation 2, $C(f)$ describes converted fractal value.

If the number of divisions of the measured section is always assumed to be ten, the revised method eliminates the division step, and unifies the measurement of all ammonite sutures relative to the ammonite to which they belong. For comparing ontogenies of two or more ammonites, it should be clearly stated which ontogenetic stage contains the first suture in the measured sequence. This can be done by denoting the whorl of the first included suture in data where shell diameter is unavailable. 


\section{SUTURE FRACTAL CONVERSION VALUES}

\begin{tabular}{|c|c|}
\hline GENUS & CONVERSION VALUE \\
\hline Lytoceras & $\mathrm{C}(f)$ step count $\div 2$ \\
\hline Gaudryceras & $\mathrm{C}(f)$ step count $\div 2$ \\
\hline Tetragonites & $\mathrm{C}(f)$ step count $\div 2$ \\
\hline Holcolytoceras & $\mathrm{C}(f)$ step count $\div 1.2$ \\
\hline Psiloceras & $\mathrm{C}(f) \div 1.55, \mathrm{C}(f) \div 1.9$ \\
\hline Dorsoplanites & $\mathrm{C}(f)$ step count $\div 1.3$ \\
\hline Perisphinctes & $\mathrm{C}(f)$ step count $\div 1.3$ \\
\hline Harpoceras & $\mathrm{C}(f)$ step count $\div 1.113$ \\
\hline Phylloceras & $\mathrm{C}(f)$ step count $\div 2.5$ \\
\hline
\end{tabular}

TABLE 1. A non-exhaustive review of conversion values for various ammonoid taxa.

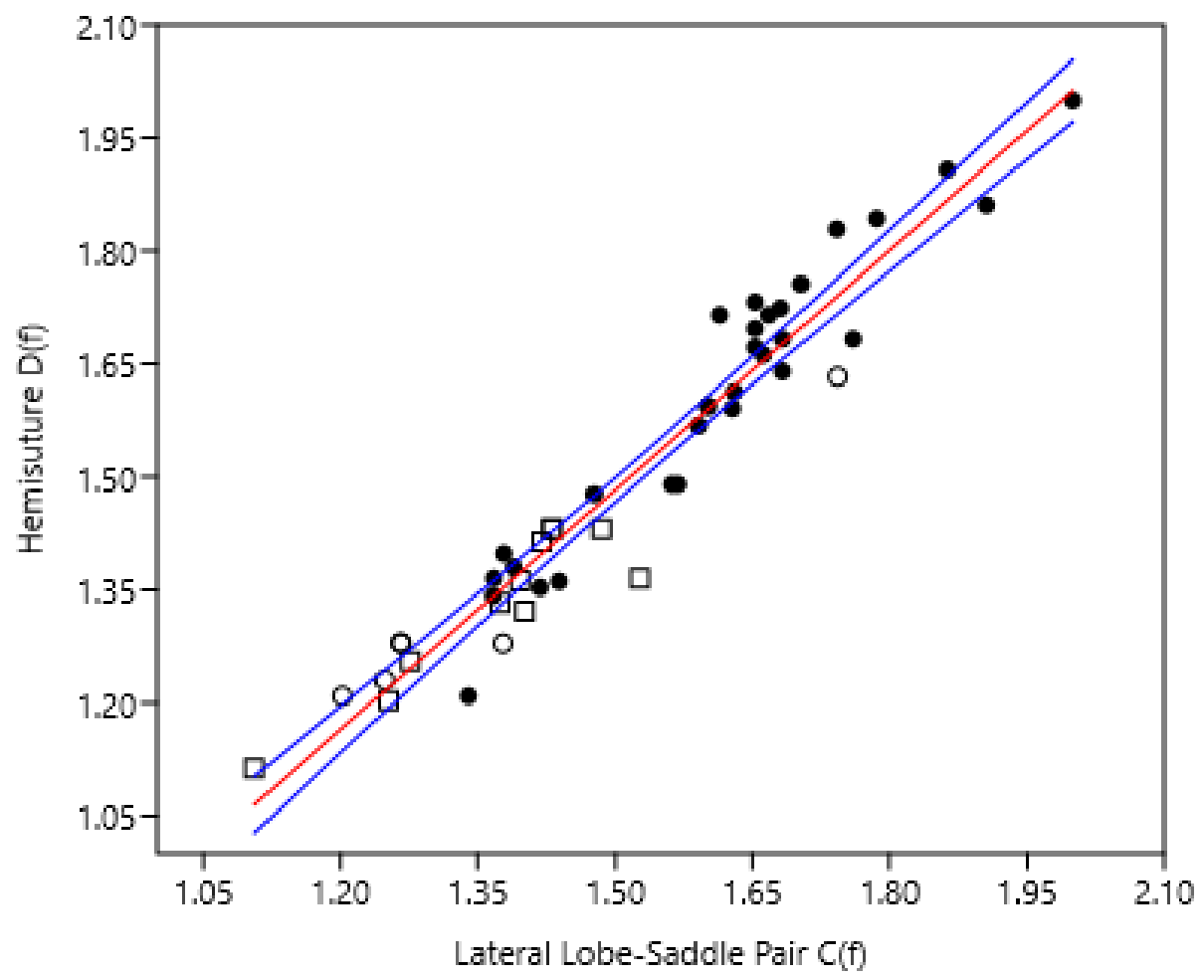

Figure 6. The fractal dimensions of ammonite hemisutures versus lateral lobe-saddle pairs using the appropriate Conversion Values from Table 1, using the program PAST [23]. The blue lines are $95 \%$ confidence. 
Suture geometry has generally always been considered a primary diagnostic tool when assigning taxonomy to a specimen [24]. The mean fractal value of all ammonite sutures is accepted to approximate $1.37[\underline{12}, \underline{25}]$. This paper heavily relies on suture tracings published by other authors, and actively sought, in vain, suture ontogenies that had previously been quantified fractally (Figure 7) $[\underline{25}, \underline{26}]$. However, it is impossible to make further comparisons from the 1990 publication, as the step length is not specified. Furthermore, the approach taken by Garcia-Ruiz et al. $[\underline{12}, \underline{25}]$ did not account for the ontogenetic stage in which the sutures were measured, and the authors noted that the method did not quantify the rate of change between sutures in the ontogenetic sequence [12].Our revised method facilitates the ability to graph entire ontogenies, such as those rarely published before [26] without access to the full undistorted hemisuture. It also enables a higher resolution of fractal measurement than the Richardson method.

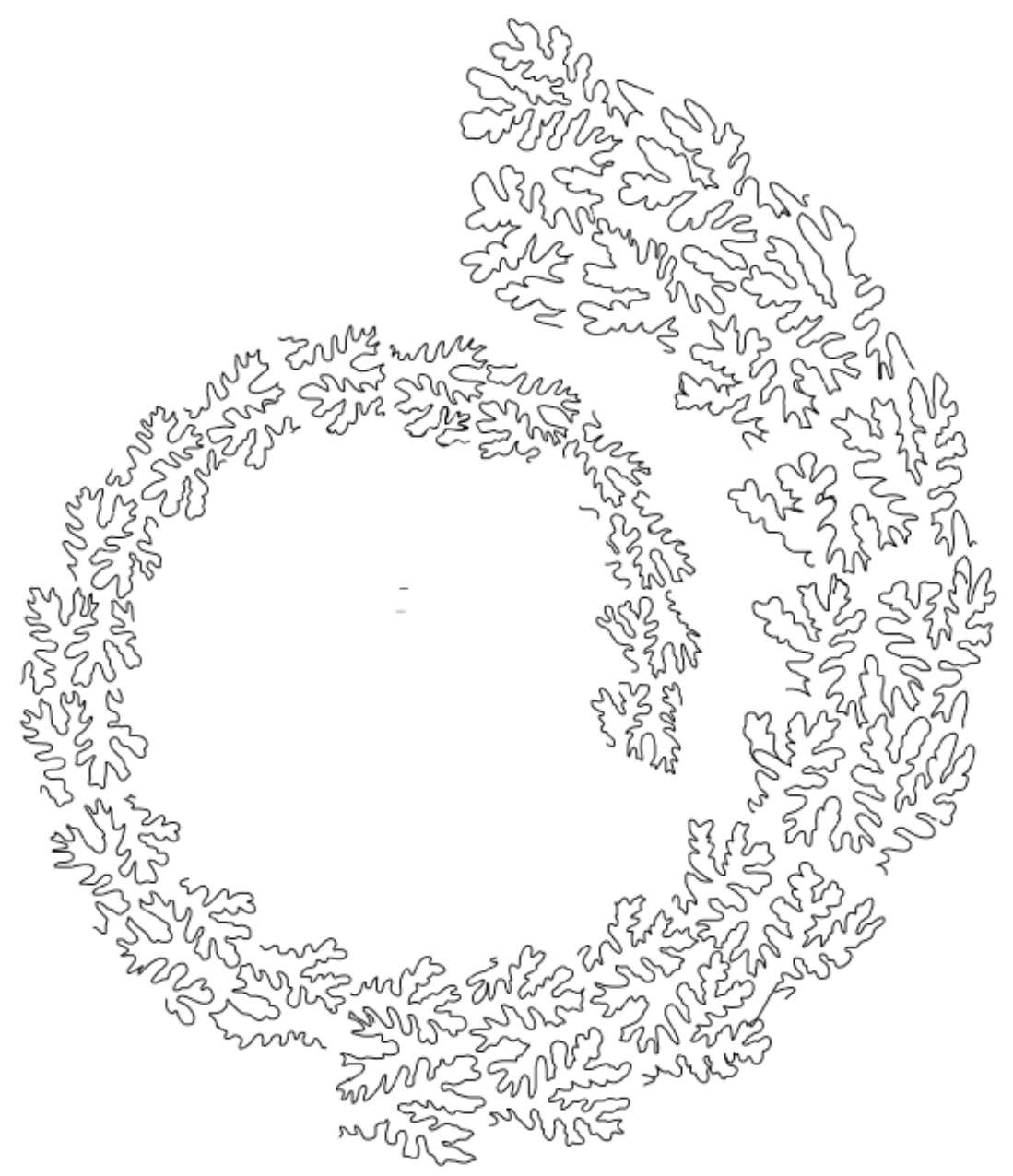


Figure 7. A tracing of one and a half whorls of Gaudryceras sacya using only lateral lobe and saddle elements. Specimen MNHN-F-R00642 from Musee National d'Histoire Naturelle, Paris. Drawn by KM.

In the Richardson Step Method, different or unknown step lengths can be used, so measurements of even the same suture may vary if different step lengths were deployed. Comparisons between fractal dimensions of previously published taxa are not reusable unless the step length is given in the publication, which it generally is not, and is the same as the step length used for other ammonites being compared. Comparing ammonites based on their own respective ontogenies rather than standard units of measurement that are arbitrary to them circumvents this issue.

\section{Acknowledgements}

We thank the reviewers of this paper. We thank Rene Hoffmann for sharing numerous out-of-print publications containing ammonite suture tracings. We thank Donald Prothero for his feedback on the explanation of our methods.

\section{References}

1. Marriott, K., 2020. “A New Approach to the Step Method for Fractal Ontogenies,” 2020th ed. Palaeontological Association Annual Meeting. Virtual Annual Meeting: Palaeontological Association, 2020. DOI: 10.13140/RG.2.2.36000.40968

2. Vicencio R., 1973. “Models for the morphology and morphogenesis of the ammonoid shell." Unpublished PhD thesis, McMaster University, Hamilton, Ontario.

3. Guex, J., 1981. “Associations virtuelles et discontinuités dans la distribution des espèces fossils: Un exemple intéressant.” Bulletin Soc. Vaudoise Sciences Naturales. Vol. 75, 179-197. DOI 10.5169/seals-277792

4. Bayer, U., 1985. "Pattern recognition problems in geology and paleontology." Springer, Berlin.

5. Damiani, G., 1986. "Significato funzionalle dell' evoluzione dei setti e delle line di sutura dei nautiloidi e degli ammonoidi." In: Pallini, G. (Ed.) Atti I Convengo Internationale: Fossili, Evoluzione, Ambiente, Pergola 1984. Tecnoscienza, Roma

6. García-Ruiz, J. M., \& Checa, A., 1993. “A model for the morphogenesis of ammonoid septal sutures.” Geobios, Vol. 26, 157-162. https://doi.org/10.1016/S0016-6995(06)80369-4

7. Lutz, T., and Boyajian, G., 1995. "Fractal Geometry of Ammonoid Sutures." Paleobiology, Vol. 21, No. 3, $329-342$.

8. Oloriz, F., Palmqvist, P., and Perez-Claros, J.A., 2007., "Shell features, main colonized environments, and fractal analysis of sutures in Late Jurassic ammonites." Lethaia, Vol. 30, No. 3, 191-204. doi:10.1111/j.1502-3931.1997.tb00461.x

9. Klug C, Hoffmann R., 2015. “Ammonoid septa and sutures. In Ammonoid Paleobiology, Volume I: from anatomy to ecology" (Eds. Klug, C.; De Baets, K.; Kruta, I.; and Mapes, R.), 45-90. Dordrecht, The Netherlands: Springer.

10. Pérez-Claros, J., Palmqvist, P., and Oloriz, F., 2002. "First and second orders of suture complexity in ammonites: a new methodological approach using fractal analysis." Mathematical Geology, 323-332.

11. Pérez-Claros, J., Olóriz, F., and Palmqvist, P., 2007. "Sutural complexity in Late Jurassic ammonites and its relationship with phragmocone size and shape: A multidimensional approach using fractal analysis." Lethaia. Vol. 40, 253-272.

12. García-Ruiz, J. M., \& Checa, A., 1993. "A model for the morphogenesis of ammonoid septal sutures." Geobios, Vol. $26,157-162$.

13. Ward, P.D., 1980. "Comparative shell shape distributions in Jurassic-Cretaceous ammonites and Jurassic-Tertiary Nautilids." Paleobiology, Vol. 6, p. 32-43.

14. Mandelbrot, B., 1982. "The Fractal Geometry of Nature.” W.H. Freeman, New York.

15. Schindewolf, O., 1953. “On development, evolution, and terminology of ammonoid suture line." Bulletin of the Museum of Comparative Zoology at Harvard College, Vol. 112, 217-237.

16. Schindewolf, O., 1960. "Studien zur Stammesgeschichte der Ammoniten." Ash Akad Wiss Lit Mainz, Math-Nat, Kl, Vol. 10, 639743, Lief 1.

17. Schindewolf, O., 1965. "Studien zur Stammesgeschichte der Ammoniten." Ash Akad Wiss Lit Mainz, Math-Nat, Kl, Vol. 13, 139238, Lief 3.

18. Schlegelmilch, R., 1976. “Die Ammoniten des suddeutschen Lias.” Gustav Fischer Verlag.

19. Schlegelmilch, R., 1976. “Die Ammoniten des suddeutschen Malms.” Gustav Fischer Verlag. 
20. Hoffmann, R., 2010. “New insights on the phylogeny of the Lytoceratoidea (ammonitina) from the septal lobe and its functional interpretation." Revue de Paleobiologie, Vol. 29, No. 1.

21. Westermann, G. E. G., 1954, Monographie der Otoitidae (Ammonoidea): Beih. Geol. Jahrb., H. 15, 364 pp., 33 pls

22. Stevens, G., 1985. "A revision of the Lytoceratinae (Subclass Ammonoidea) including Lytoceras taharoaense n. sp., Upper Jurassic, New Zealand." New Zealand Journal of Geology and Geophysics, 164-165.

23. Hammer, Ø., Harper, D.A.T., and P. D. Ryan, 2001. PAST: Paleontological Statistics Software Package for Education and Data Analysis. Palaeontologia Electronica, 4, No. 1.

24. Kullmann, J., and Wiedmann, J., 1970. "Significance of sutures in phylogeny of Ammonoidea." The University of Kansas Paleontological Contributions, 1-25.

25. García-Ruiz, J. M., Checa, A., and Rivas, P. 1990. “On the origin of ammonoid sutures.” Paleobiology, Vol. 16, No. 3 pp. $349-354$.

26. Hoffmann, R. and Maisch, M., 2018. "Systematics and phylogenetic position of the lytoceratid ammonite genus Holcolytoceras Spath, 1924 (Cephalopoda, Ammonoidea) from the Lower Pliensbachian of Europe." Neues Jahrbuch für Geologie und Paläontologie 288, No. 2. 